Шилова О.Е.

\title{
Деятельность ЮНЕСКО в сфере художественного образования
}

Аннотация: В статье рассматривается деятельность ЮНЕСКО в сфере художественного образования. Рассматриваются цели создания такой политики организации и конкретные мероприятия, организуемые в рамках международного сотрудничества в сфере художественного образования. Исследуются рекомендательные документы ЮНЕСКО в сфере образования и художественного образования в частности. Представлены программы ЮНЕСКО по развитию художественного образования. Автор идентифицирует причины создания международной политики сотрудничества государств в сфере художественного образования. На основе анализа документов ЮНЕСКО автор выделяет следующие причины создания такой политики: развитие креативности мышления человека; способствование социальному миру, толерантности и солидарности; способствование устойчивому развитию. Автором такюе выделяются две функции художественного образования, которые концептуализированы в документах ЮНЕСКО: инструментальная функция художественного образования, т.е. его использование в качестве средства и метода при изучении общеобразовательньх дисциплин, а также, собственно, миросозидательная функция. Автор утверждает, что документы разработанные ЮНЕСКО в сбере художественного образования имеют незначительное влияние на национальные образовательные программы в силу их рекомендательного характера. В тоже время, в статье обращается внимание на реализацию конкретных проектов под эгидой ЮНЕСКО, которые несмотря на ограниченность своего влияния отличаются высокой эффективностью.

Review: The article is devoted to the activity performed by UNESCO in the sphere of art education. The author of the article analyzes the goals of creating such a policy of UNESCO as well as particular activities and events organized within the framework of international cooperation in the sphere of art education. The author also studies recommendations and guidelines of UNESCO in the sphere of education in general and art education in particular. Shilova describes UNESCO programs aimed at development of art education and identifies why the international cooperation policy was created in the sphere of art education. Based on the analysis of UNESCO documents, the author defines the following reasons for creating the aforesaid policy: development of creative thinking; growth of social peace, tolerance and mutual respect and a growing contribution to sustainable development. Shilova also emphasizes the two functions of art education that were conceptualized in UNESCO documents: instrumental function of art education, i.e. using art as a mean and method of teaching general disciplines, and the function of creating the picture of the world. Based on the author, documents prepared by UNESCO to be used in the sphere of art education have rather insignificant influence on national educational programs due to their non-regulatory nature. At the same time, Shilova focuses on the implementation of particular projects under the guidance of UNESCO which still turned out to be quite efficient.

Ключевые слова: ЮНЕСКО, международные отношения, художественное образование, международное сотрудничество, искусство, образование, рекомендации, обсерватории, принципы, проекты.

Keywords: UNESCO, international relations, art education, international cooperation, art, education, recommendations, observatories, principles, projects.

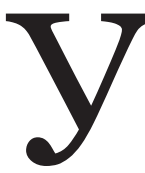

став Организации Объединенных Наций по вопросам образования, науки и культуры устанавливает в качестве целей создания данной организации «...развитие народного образования и распространение культуры, сотрудничая с государствами - членами Организации по их просьбе в деле расширения просветительной деятельности...», а также «...сохранению, увеличению и распространению знаний (...), произведений искусства (...) рекомендуя заинтересованным странам заключение соответствующих международных конвенций, поощряя сотрудничество народов во всех областях умственной деятельности, международный обмен лицами, работающими в области образования, науки и культуры...». Очевидно, что такие направления деятельности ЮНЕСКО явно свидетельствуют о том, что в обязанности данной международной ор- 
ганизации входит как организация и развитие международного сотрудничества в сфере культуры и искусств, так и международного сотрудничества в сфере образовательной и просветительской деятельности ${ }^{1}$. Более того, как и любая универсальная международная организация, образованная под эгидой ООН, ее основная функция заключается в поддержании мира между нациями (миросозидательная функция). Таким образом, ЮНЕСКО вот уже более чем за 6о-летний срок своего существования «мобилизует международное сообщество с целью поддержки образовательной и художественной деятельности для того чтобы улучшить диалог между людьми и построить между ними мирные отношения ${ }^{2}$.

Действительно, устав организации свидетельствует о том, что первоочередной функцией ЮНЕСКО, как и большинства агентств образованных под эгидой ООН, является примирительная функция, о чем свидетельствует преамбула этого текста ${ }^{3}$ Как следствие, любая деятельность данной организации - в том числе и деятельность в сфере художественного образования - имеет в качестве первоочередной цели миротворческую. Данный ход мысли подтверждается и в научных исследованиях касающихся изучения деятельности данной организации. Так, например, утверждается, что «искусство являясь инструментом толерантности, социальной солидарности и миросозидательную средством в современных мультикультурных, взаимосвязанных обществах. Молодые люди должны обучатся любви к искусству и практиковать его - это приведет к лучшему взаимопониманию между ними. Такая любовь к искусству должна культивироваться с самых ранних лет и поддерживаться в течении всех лет жизни. В нашем понимании, обучение креативности и искусствам способствует построению мирных обществ»4. Таким образом, как Устав организации, так и научная доктрина позволяют утверждать, что деятельность ЮНЕСКО в любой

\footnotetext{
${ }^{1}$ См. подробнее о целях создания и направлениях деятельности организации, например: UNESCO, UNESCO World Report: Investing in Cultural Diversity and Intercultural Dialogue, UNESCO, 2009, 409 p.

${ }^{2}$ L. O 'Farrell, Sh. Schonmann, E. Wagner, International Yearbook for Research in Arts Education 2/2014, Waxmann Verlag, 2014. P. 18.

3 Так в одной из первых строк преамбулы устава ЮНЕСКО мы обнаружим следующую фразу: «мысли о войне возникают в умах людей, поэтому в сознании людей следует укоренять идею защиты мира».

4 Там же.
}

сфере (в том числе и в сфере художественного образования) носит миросозидательную направленность.

Тем не менее, если не ограничивать анализ деятельности ЮНЕСКО лишь анализом общих документов, регулирующих функционирование данной организации, а обратиться именно к тем из них которые направлены на организацию международного сотрудничества в сфере образования (в частности художественного), то можно обнаружить что деятельность данной организации также преследует и другие цели.

Несмотря на продолжительный опыт деятельности данной организации в сфере развития международного сотрудничества в области образования, культуры и искусств, сотрудничество именно в сфере художественного образования получило свое развитие совсем недавно, так как образование в данной сфере является лишь незначительной частью общеобразовательных процессов (т.е. узкопрофильной деятельностью в сфере общего образования). Тем не менее, название одной из Резолюций организации ${ }^{5}$ само свидетельствует о том какую важность приобрело именно художественное образование в современном мире и почему организация стала уделять данному виду образования особое внимание. Действительно, в резолюции ЮНЕСКО под названием «Стимулирование художественного образования и креативности в школах как часть строительства мирной культуры ${ }^{6}$, помимо ставки на содействие мирному сосуществованию народов - что, как мы уже отметили, является целью практически любой международной универсальной организации - ставка делается и на стимулирование креативности в процессе обучения. Иначе говоря, как отмечает Генеральный секретарь ЮНЕСКО, «художественное образование носит первостепенную значимость в связи с тем, что оно способствует развитию креативности ума, которая, в свою очередь, является неотъемлемым элементом развития обществ, где центральным элементом является модернизация, инновации, научный и технический прогресс»7.

Данная инициатива ЮНЕСКО, направленная на продвижение креативности, в том чис-

${ }^{5}$ Resolution adopted on the report of Commission IV at the 25th plenary meeting, on 16 November 1999.

6 "Promotion of arts education and creativity at school as part of the construction of a culture of peace"

${ }^{7}$ UNESCO, Records of the General Conference. $30^{\text {th }}$ session, Paris, 26 October to 17 November 1999, Vol. 1. Resolutions. UNESCO, 2000. P. 69, 70. 
ле посредством художественного образования, не была первой и единственной. Так, например, по итогам конференции по образованию, проведенной под эгидой ЮНЕСКО еще в 1996 г., Ж. Дэлором был подготовлен, ставший в последствии известным, доклад под названием «Образование: сокрытое сокровище» ( Learning: the treasure within), где были систематизированы современные тенденции в системе образования, одной из которых стало развитие креативности учеников. Совсем недавно, Генеральный секретарь ЮНЕСКО Ирина Бокова, также обратила внимание на необходимость развития такой составляющей современных систем образования как стимулирование развития креативности у обучающихся: «Мир изменяется, а образование тоже должно измениться. Сегодня, каждый человек должен обладать определенными навыками, которые должны позволить ему совладать с изменяющимся миром и в полной мере использовать все возможности. Это требует образованию креативности, образованию солидарности, образованию устойчивости (устойчивому развитию)» ${ }^{8}$.

Как следствие, в указанных документах ЮНЕСКО художественное образование рассматривается как средство адаптации людей к меняющемуся миру; как средство стимуляции креативности и, как следствие, стимулирование инноваций и модернизации экономики; как средство форматирования мировоззрения с целью имплементации в жизнедеятельность идей устойчивого развития.

Стоит обратить внимание что уже на ранних этапах развития международного сотрудничества в сфере художественного образования, а именно во время парижской конференции 1999 г. помимо концентрации внимания на развитии креативности у участников образовательного процесса, было обращено внимание и на междисциллинарном подходе к художественному образованию. Так, в призыве Генерального секретаря организации на данной конференции отмечалось, что междисциплинарный подход в образовании является «фундаментальным, так как позволяет молодым людям понять универсальную природу мира»9. Иначе говоря, официальная позиция орга-

${ }^{8}$ UNESCO, Rethinking Education in a Changing World, Meeting of the Senior Experts' Group, Paris, 12-14 February 2013, UNESCOP. 23.

${ }^{9}$ UNESCO, Records of the General Conference. $30^{\text {th }}$ session, Paris, 26 October to 17 November 1999, Vol. 1. Resolutions. UNESCO, 2000. P. 70. низации по данному вопросу заключается в том, что художественное образование рассматривается как междисциплинарный элемент системы образования. Более того, в призыве Генерального секретаря также отмечается, что художественное образование способствует развитию культурного разнообразия, что еще раз подтверждает важность миросозидательной функции данного образования в глазах организации. Таким образом, уже на ранних стадиях развития международного сотрудничества в сфере художественного образования в рамках ЮНЕСКО, организацией были высказаны идеи о необходимости интеграции художественного образования в образовательные программы технических, научных и других общеобразовательных программ.

Междисциплинарный подход и использование художественного образования при преподавании других предметов демонстрирует двусторонний подход ЮНЕСКО к данному вопросу. Во-первых, художественное образование воспринимается организацией как $и н-$ струмент, или дополнительное общеобразовательное средство ("learning through the arts/culture"). Данный подход заключается в использовании искусства и художественного образования в рамках общеобразовательных процессов как средства улучшения качества образовательного процесса и его эффективности. Иначе говоря, здесь речь идет об использовании художественного образования как общеобразовательного средства, применимого в любом преподавательском процессе, предмете и науке. Во-вторых, помимо такого сугубо инструментального подхода (instrumental approach) организацией рекомендуется государствам использовать художественное образование в национальных образовательных программах как миросозидательное средство. Иначе говоря, собственно художественное образование ("learning in the arts/culture”) должно использоваться с целью поддержания социального мира и солидарности посредством формирования в рамках образовательного процесса открытых личностей способных ужиться в мультикультурном пространстве.

Таким образом, изначально международное сотрудничество в сфере художественного образования, организованное в рамках ЮНЕСКО, было предназначено для стимулирования государств на расширение роли художественного образования в их системах общего образования. Так, ЮНЕСКО пресле- 
довало цель совершенствования образовательных процессов с целью формирования целостных личностей в современном мире, способных к инновационному и креативному мышлению, критичности в оценках, а также обладающих высокими коммуникативными и коммуникационными навыками на межличностном уровне. В итоге, по словам организации ${ }^{10}$, такой обновленный подход к образованию должен способствовать не только формированию социального мира и солидарности, но также предупредить формирование стандартизированного мышления и способствовать имплементации в жизнь идей устойчивого развития.

Значительный вклад в организацию международного сотрудничества в сфере художественного образования, а также его развития в государствах внесли две не так давно состоявшиеся конференции, организованные под эгидой ЮНЕСКО.

Две конференции ЮНЕСКО, посвященные художественному образованию, состоявшиеся в Лиссабоне в 2006 г. и в Сеуле в 2010 г. позволили определить стратегии развития современного художественного образования. Обе конференции стали знаковыми событиями для международного сотрудничества в сфере художественного образования. Действительно, на обеих конференциях присутствовало несколько сотен представителей из почти 100 стран мира, которые поделились опытом организации художественного образования на национальном уровне. Более того, основным вкладом данных конференций в развитие художественного образования стали разработанные по итогам работы данных конференций документы: Дорожная карта художественного образования (Road Map for Arts Education), разработанная в рамках лиссабонской конференции и Сеульская повестка дня «Цели развития художественного образования" (Seoul Agenda: Goals for the Development of Arts Education), разработанная по итогам сельской конференции.

Дорожная карата художественного образования ЮНЕСКО, разработанная в рамках Всемирной конференции по образованию в области искусств, состоявшейся 6-9 марта 2006 г. в Лиссабоне, направлена на изучение роли такого образования в удовлетворении

${ }^{10}$ UNESCO, Rethinking Education in a Changing World, Meeting of the Senior Experts' Group, Paris, 12-14 February 2013, UNESCOP. 23 потребности в создании творческого потенциала и подчеркивает важность стратегий, необходимых для интеграции или развития художественного образования в рамках учебного процесса. Данный документ предназначен для того чтобы донести до всех акторов (в первую очередь участников системы образования) важность художественного образования и его существенную роль в повышении качества образования. В документе представлен наиболее передовой и успешный опыт в области художественного образования. Таким образом, он представлен как документ предназначенный для практической реализации, то есть принятия конкретных мер в образовательных системах государств с целью интеграции или продвижения художественного образования в различных образовательных процессах.

Данный документ стал первым в своем роде, так как он исключительно посвящен вопросам художественного образования. Действительно, ранее документы ЮНЕСКО касавшиеся художественного образования уделяли ему лишь ограниченное внимание, тогда как основная их часть была посвящена вопросам образования в целом. Более того, документ содержит конкретные рекомендации по интеграции художественного образования и его развития в рамках общеобразовательной системы. Данные рекомендации предназначены как для, собственно, государств-членов с целью соответствующих изменений и адаптации их систем образования и, так и преподавателей, родителей, творческих работников и директоров школ и других учебных заведений, с тем чтобы они на своем уровне моги предпринять меры по интеграции или развитию художественного образования.

Рекомендации изложенные в данном документе стали итогом многочисленных региональных конференций и круглых столов, часть из которых была проведена под эгидой $\mathrm{HHECKO}^{11}$. В рекомендациях в частности рассматриваются проблемы по имплементации и развитию художественного образования отдельных государств, а также предлагается ряд конкретных мер по разрешению данных проблем. Основные рекомендации сформированы в отношении различных субъектов (государства, преподавателей, других международных организации и т.п.) по следующим

\footnotetext{
${ }^{11}$ См. подробнее например L. Joubert, Educating in the Arts: The Asian Experience: Twenty-Four Essays, Springer Science \& Business Media, 2008.
} 
направлениям: принятие конкретных мер по имплементации и развитию художественного образования; сотрудничество с другими субъектами образовательного процесса; и оценка эффективности предпринятых мер.

Сеульская повестка дня «Цели развития художественного образования" стала итоговым документом сельской конференции, проведенной 25-28 мая 2010 г. в столице корейской республики. Данный документ, как и Дорожная карта посвящен исключительно вопросам художественного образования и его роли в системе образования. Тем не менее, в отличие от Дорожной карты он более краток и прост в изложении, а изложенные в нем мысли представлены в виде систематизированных принципов, что несомненно будет способствует эффективной реализации заложенных в нем целей. Повестка дня, как и Дорожная карта содержат рекомендации различным акторам системы образования с целью «...полной реализации потенциала качественного художественного образования в целях позитивного обновления систем образования, решения ключевых социальных и культурных задач...». Более того, текст содержит ряд рекомендаций по реализации конкретных мероприятий в сфере художественного образования, что придает ему высокую практическую значимость.

В преамбуле документа отмечается значение художественного образования, которое по идее составителей данного текста должно «удовлетворить потребности учащихся, живущих в быстро меняющемся мире, который характеризуется, с одной стороны, выдающимися технологическими достижениями, а с другой, постоянными проявлениями несправедливости в социальной и культурной областях". Иначе говоря, документ, как и предыдущие инициативы организации, настаивает на миротворческой миссии (поддержания социального мира и солидарности в поликультурном пространстве) художественного образования, а также на «потребности в творческих трудовых ресурсах, способных адаптироваться к реалиям постиндустриальных экономик”.

Основная часть документа, собственно, содержит цели развития художественного образования. Их три:

1. Обеспечить доступность образования в области искусств как одного из фундаментальных и устойчивых компонентов качественного обновления образования. Данная цель развития художественного образования выражается в реализации мер с целью его ис- пользования: в качестве основы для сбалансированного, творческого, познавательного, эмоционального, эстетического и социального развития; в качестве конструктивной трансформации образовательных систем и структур; как систему обучения на протяжении всей жизни человека и как средство передачи опыта от поколения к поколению.

2. Обеспечить высокое качество концептуализации и осуществления деятельности и программ художественного образования. Эта цель развития художественного образования направлена на развитие в государствах: стандартов художественного образования, соответствующих местным потребностям, инфраструктуре и культурному окружению; систем обеспечения профессиональной подготовки педагогов по данным предметам; стимулирование обмена между исследованиями и практикой художественного образования; содействия сотрудничеству между педагогами и творческими работниками, а также организации партнерства в области художественного образования.

3. Применять принципы и практику художественного образования для содействия решению социальных и культурных проблем, стоящих перед современным миром. В рамках данной цели развития художественного образования государствам рекомендуется: использовать художественное образование для увеличения творческого и инновационного потенциала общества; признать существование связи между художественным образованием и социальным и культурным благополучием и развивать его в данном аспекте; развивать художественное образование с целью повышения социальной ответственности, сплоченности и содействия межкультурного диалога; использовать художественное образование с целью решения современных глобальных проблем, утверждения мира и устойчивого развития.

Помимо рассмотренных выше рекомендательных актов ЮНЕСКО в сфере художественного образования - реализация которых осуществляется самими государствами и эффективность которых в силу необязательного характера данных актов зависит от имплементирующих их государств ${ }^{12}$ - орга-

12 Так, например, по данным проведенного ЮНЕСКО в 2009 г. наблюдения по имплементации государствами рекомендаций изложенных в Дорожной карте из ответивших на опрос государств лишь полови- 
низация, совместно с государствами и другими организациями, предпринимает ряд конкретных проектов в данной сфере. Несмотря на их ограниченный характер, именно данные проекты стали конкретным вкладом ЮНЕСКО в продвижение идей о развитии художественного образования в современном мире, выраженных в рассмотренных выше актах организации.

Одной из инициатив ЮНЕСКО по продвижению художественного образования в мире которою организация реализует как сама, так и при сотрудничестве других акторов сферы образования и искусств - стала организация Международных недель художественного образования (International Arts Education Week). Данный проект, организуемый ежегодно ${ }^{13}$ в последней неделе мая, был создан Резолюцией Генеральной ассамблеи организации ${ }^{14}$. В соответствии с данным решением ЮНЕСКО, такие недели художественного образования предназначены для стимулирования государств-членов, представителей общественности, профессиональных организаций с целью организации соответствующих мероприятий, предназначенных для популяризации художественного образования ${ }^{15}$.

Совместное с университетами различных государств создание кафедр по изучению художественного образования стало еще одним проектом ЮНЕСКО в области художественного образования ${ }^{16}$. Впервые такая кафедра

на из них использовала рекомендации организации по имплементации и продвижению художественного образования при проведении реформ их систем образования. Основной проблемой стал недостаток государственного финансирования. UNESCO, Report of the Survey Results on the Implementation of the Road Map for Arts Education, Seoul, Korea, 2010. P.3

13 По данным организации в связи с финансовыми проблемами данная неделя не была организована в 2013 г. L. O 'Farrell, Sh. Schonmann, E. Wagner, International Yearbook for Research in Arts Education 2/2014, Waxmann Verlag, 2014. P. 18.

${ }^{14}$ Resolution 36/C55 adopted on the report of the CLT Commission at the 17 th plenary meeting, on 10 November 2011.

15 См. подробнее о проводимых в рамках данных недель мероприятий: Final report, First celebration of International Arts Education Week (21-27 May 2012). http://www.unesco.org/new/fileadmin/MULTIMEDIA/ HQ/CLT/pdf/FINALREPORT_EN.pdf

${ }^{16}$ Создание таких кафедр осуществляется совместно университетами и ЮНЕСКО на основе соглашения подписываемого Генеральным секретарем ЮНЕСКО и ректором соответствующего университета. Общие принципы создания таких кафедр уже давно были разработаны ЮНЕСКО в рамках програм- была создана в канадском королевском университете (Queen's University) в 2007 г. «Кафедра искусств и обучения» (Chair in Arts and Learning) была создана в этом университете с целью создания системы, на основе которой проводятся исследования, обучение и информирование по вопросам художественного образования. Позднее (в 2010 г.) ЮНЕСКО реализовала проект по созданию подобной кафедры в Нюрнбергском университете (FriedrichAlexander-University Erlangen-Nuremberg). «Кафедра по искусству и культуре в образовании» (Chair in Arts and Culture in Education) занимается исследованием влияния художественного образования на социальные условия жизни людей. Обе кафедры плотно сотрудничают с органами ЮНЕСКО и активно участвуют в реализации отдельных проектов этой организации в области художественного образования.

Схожим проектом стало создание обсерваторий по художественному образованию. Проект был подготовлен по итогам Симпозиума экспертов ЮНЕСКО по художественному образованию в Азии (UNESCO Expert Symposium on Arts Education in Asia), состоявшемся в Гонконге в январе 2004 г. По итогам работы данного симпозиума был разработан план действий азиатского-тихоокеанского региона («Asia-Pacific Action Plan»), основным вкладом которого стал призыв к необходимости создания обсерваторий по художественному образованию. С тех пор было создано несколько таких обсерваторий: в Мельбурне; Гонконге; Сингапуре; Алма-Ате; Сеуле и Крайстчерче (Новой Зеландии). Данные обсерватории предназначены для популяризации и распространения информации о художественном образовании с целью оказания влияния на политику в сфере художественного образования. Обсерватории плотно взаимодействуют с ЮНЕСКО по вопросам художественного образования и принимают участие в различных мероприятиях организуемых ЮНЕСКО, а их деятельность отличается от деятельности кафедр тем, что она носит более прикладную (а не научную) направленность.

Немаловажным проектом ЮНЕСКО в сфере художественного образования стал проект разработанный московским бюро ЮНЕСКО под

мы по созданию кафедр (UNITWIN/UNESCO Chairs Programme), существующей с 1992 г. По вопросу условий создания таких кафедр см. подробнее: UNESCO, Guidelines and procedures for the UNITWIN/UNESCO Chairs Programme, ED/HED/UNITWIN/2006/PI/1 rev. 4 UNESCO, 2009 
названием «Художественное образование в странах СНГ: развитие творческого потенциала в XXI веке» ("Arts Education in CIS countries: Building Creative Capacities for XXI Century”). Проект реализуется совместным и усилиями ЮНЕСКО и Межгосударственного фонда гуманитарного сотрудничества государств-участников (Intergovernmental Foundation for Educational, Scientific and Cultural Cooperation) $\mathrm{CH \Gamma}$ (далее: МФГС), а также соответствующих министерств (культуры и образования) и других учреждений сферы культуры и образования государств СНГ и предназначен для совершенствования культурной и образовательной политики в сфере художественного образования, а также улучшения взаимодействия между министерствами культуры и министерствами образования стран СНГ посредством проведения аналитических исследований в области художественного образования.

Реализация проекта «Художественное образование в странах СНГ: развитие творческого потенциала в XXI веке» потребовала подписания соглашения между ЮНЕСКО и МФГС, которое состоялось 12 октября 2009 г. Основной деятельностью в рамках данного проекта стало проведение аналитических исследований в области художественного образования в странах СНГ и сравнение национальных политик данных государств со стандартами и рекомендациями ЮНЕСКО, изложенными в Дорожной карте и Сеульской повестке дня, а также выражение конкретных рекомендаций данным государствам по совершенствованию художественного образования в них. Сотрудничество в рамках данного проекта является довольно плотным и интенсивным (в сравнении с другими проектами) и привело в частности к созданию сети взаимодействия заинтересованных лиц в целях развития художественного образования, и даже к созданию совместного института - Обсерватории художественного образования государств-участников СНГ (Observatory on Arts Education in the CIS Countries) ${ }^{17}$.

Итак, причинами создания международной политики ЮНЕСКО в сфере художественного образования стали: необходимость развития креативности мышления человека в современном мире; способствование социальному миру и солидарности в мулитикультурной среде; способствование устойчивому развитию. В качестве функций художественного образования ЮНЕСКО признает: инструментальную функцию художественного образования, т.е. его использование в качестве средства и метода при изучении общеобразовательных дисциплин, а также, собственно, миросозидательную функцию, которая раскрывается в процессе обучения искусствам и способствует развитию толерантности, социального мира и солидарности посредством формирования в рамках образовательного процесса открытых личностей способных ужиться в мультикультурном пространстве.

\section{Библиография:}

1. L. O 'Farrell, Sh. Schonmann, E. Wagner, International Yearbook for Research in Arts Education 2/2014 , Waxmann Verlag, 2014. P. 18.

2. L. Joubert, Educating in the Arts: The Asian Experience: Twenty-Four Essays, Springer Science \& Business Media, 2008.

3. UNESCO, Records of the General Conference. 30th session, Paris, 26 October to 17 November 1999, Vol. 1. Resolutions. UNESCO, 2000.

4. UNESCO, Rethinking Education in a Changing World, Meeting of the Senior Experts' Group, Paris, 1214 February 2013, UNESCOP.

5. UNESCO, Report of the Survey Results on the Implementation of the Road Map for Arts Education, Seoul, Korea, 2010.

6. UNESCO, Final report, First celebration of International Arts Education Week (21-27 May 2012). http://www. unesco.org/new/fileadmin/MULTIMEDIA/HQ/CLT/pdf/FINALREPORT_EN.pdf

7. UNESCO, Guidelines and procedures for the UNITWIN/UNESCO Chairs Programme, ED/HED/UNITWIN/2006/ PI/1 rev. 4 UNESCO, 2009

\footnotetext{
${ }^{17}$ http://ae.cis.iite.unesco.org/observatory/index.php/ru/
} 


\section{References (transliterated):}

1. L. O'Farrell, Sh. Schonmann, E. Wagner, International Yearbook for Research in Arts Education 2/2014, Waxmann Verlag, 2014. R. 18.

2. L. Joubert, Educating in the Arts: The Asian Experience: Twenty-Four Essays, Springer Science \& Business Media, 2008.

3. UNESCO, Records of the General Conference. 30th session, Paris, 26 October to 17 November 1999, Vol. 1. Resolutions. UNESCO, 2000.

4. UNESCO, Rethinking Education in a Changing World, Meeting of the Senior Experts' Group, Paris, 12-14 February 2013, UNESCOR.

5. UNESCO, Report of the Survey Results on the Implementation of the Road Map for Arts Education, Seoul, Korea, 2010.

6. UNESCO, Final report, First celebration of International Arts Education Week (21-27 May 2012). http://www. unesco.org/new/fileadmin/MULTIMEDIA/HQ/CLT/pdf/FINALREPORT_EN.pdf

7. UNESCO, Guidelines and procedures for the UNITWIN/UNESCO Chairs Programme, ED/HED/UNITWIN/2006/PI/1 rev. 4 UNESCO, 2009 